\title{
Análise da viabilidade econômica da produção de leite a pasto e com suplementos na região dos Campos Gerais - Paraná
}

\author{
Evaluation of the economic viability of milk production on pasture and supplements \\ in the region of Campos Gerais - Paraná, Brazil \\ Hernani Alves da Silva ${ }^{\mathrm{I}^{*}}$ Henrique Soares Koehler ${ }^{\mathrm{I}}$ Anibal de Moraes ${ }^{\mathrm{I}}$ \\ Vania Di Addario Guimarães ${ }^{\text {II }}$ Elaine Hack ${ }^{I}$ Paulo César de Faccio Carvalho ${ }^{\text {III }}$
}

RESUMO

Com o objetivo de avaliar a rentabilidade da produção de leite no sistema de produção integração lavourapecuária, foi conduzido um experimento, no período de julho de 2004 a abril de 2005, em Castro, Paraná. O delineamento utilizado foi de blocos ao acaso com quatro tratamentos e três repetições, com os tratamentos correspondendo a diferentes níveis de suplementação. Os tratamentos utilizados foram: 1 pastagem $+20 \%$ de suplementação, com Dieta Total Misturada (DTM), suficiente para mantença e produção de 28 litros vaca ${ }^{-1}$ dia $^{-1} ; 2$ - pastagem $+45 \%$ de suplementação; 3 - pastagem $+65 \%$ de suplementação; e 4 - pastagem + $100 \%$ de suplementação. A área experimental utilizada foi de 32,40ha, com 22,4ha no inverno, implantada com o consórcio azevém anual (Lolium multiflorum L.) e aveia preta (Avena strigosa Schreb.), dividida em 12 piquetes. No verão foi utilizada área de 10,0ha, com Quicuio (Pennisetum clandestinum), dividida também em 12 piquetes. Em cada repetição, foram utilizados quatro animais "testers", sendo três vacas da raça HPB e uma da raça Jérsei. O sistema de pastejo adotado foi o de lotação contínua, com carga variável. Foram utilizados animais reguladores para controlar a altura do pasto, mantida em torno de $20 \mathrm{~cm}$. Foram avaliadas, duas vezes por semana, a produção individual de leite das vacas, e a cada duas semanas a percentagem de gordura, a percentagem de proteína e a contagem de células somáticas no leite. A análise econômica foi realizada utilizando a metodologia proposta pelo Sistema de Acompanhamento do Custo de Produção de Leite no Paraná - FAEP. O tratamento 1 , com $20 \%$ de suplementação, apresentou o melhor resultado econômico, com custo operacional total de $R \$ 0,4635$ litro $^{-1}$, e margem líquida de $R \$$ 0,13 litro $^{-1}$.

Palavras-chave: sistemas de produção, análise econômica, pastagens, forrageiras.

\begin{abstract}
Aiming to evaluate the profitability of milk production under an integrated dairy-crop system, on experiment was carried out at a commercial farm, of Paraná State, from July 2004 up to April 2005. A completely randomized block design, with four treatments, corresponding to different supplementation levels, with three replicates was applied. Treatments were pastures supplemented with $20 \%$, $45 \%, 65 \%$ and $100 \%$ of supplementation (total diet calculated to give maintenance and milk production of $28 \mathrm{~kg} / \mathrm{cow}$ per day). The experimental area contained 32.4 hectares, being 22.4 hectares used during winter, composed of a mixture of annual ryegrass (Lolium multiflorum L.) and black oat (Avena strigosa Schreb), divided into twelve paddocks. During summer an area of 10 hectares was used, with Kikuyo (Pennisetum clandestinum) also divided in 12 paddocks. Three Holstein and one Jersey cows were used in each experimental unit as testers animals. The grazing system was continuous, with variable stocking. Put-and-take animals were used to control ward height, maintained around $20 \mathrm{~cm}$. Individual milk production was evaluated twice a week and percentage of fat, protein and somatic cell count were evaluated weekly. The economic analysis was proceeded using the methodology proposed by the Milk Cost Follow Up System of Paraná State. During the evaluation period, treatment 1 with $20 \%$ of supplementation showed the best results, with a total operational cost of $R \$ 0.4635$ liter $^{-1}$ and net income of $R \$ 0.13$ liter $^{-1}$.
\end{abstract}

Key words: production system, economical analysis of milk production, pastures, forage.

\section{INTRODUÇÃO}

A bacia leiteira da região do ABC, Campos Gerais do Estado do Paraná, é conhecida por sua

\footnotetext{
IDepartamento de Fitotecnia e Fitossanitarismo, Setor de Ciências Agrárias, Universidade Federal do Paraná (UFPR). Rua dos Funcionários, 1540, 80035-050, Curitiba, PR, Brasil. E-mail: hernani@castrolanda.coop.br. Autor para correspondência.

IIDepartamento de Economia Rural, UFPR, Curitiba, PR, Brasil.

IIIDepartamento de Plantas Forrageiras e Agrometeorologia, Universidade Federal do Rio Grande do Sul (UFGRS). Porto Alegre, RS, Brasil.
} 
eficiência e produtividade na atividade leiteira, tendo por característica os sistemas de confinamento total e semi-confinamento altamente desenvolvidos. A maioria dos produtores dessa região vem sofrendo, nos últimos anos, problemas de adaptação da produção aos preços pagos pelo mercado, principalmente, em relação aos custos de produção, que sofrem aumentos generalizados em rações, medicamentos, combustível, transporte, fertilizantes, defensivos e sementes, entre outros.

Considerando que a alimentação com mistura de concentrados seja o principal custo de produção, a maneira de aumentar a rentabilidade do produtor estaria relacionada à utilização adequada dos recursos de baixo custo disponíveis, como a pastagem. O “conceito-chave” seria o pastejo em substituição aos custos com combustível, máquinas e equipamentos, utilizados no processo de colheita da forragem. O benefício imediato é de caráter econômico, com redução nos custos de produção de leite. Além disso, os investimentos em instalações, especialmente aquelas destinadas ao abrigo dos animais e maquinários, são menores quando se comparam sistemas a pasto com aqueles em confinamento (MATOS, 2002).

A produção de leite a pasto é o sistema mais econômico. A pastagem é a fonte de nutrientes mais econômica em qualquer parte do mundo, mas principalmente em países em desenvolvimento. Além do aspecto econômico, a utilização mais racional das pastagens auxilia na preservação dos recursos renováveis e permite a produção de leite sob condições mais naturais (HOLMES, 1995). De acordo com VILELA et al. (1996), a análise de experimentos conduzidos na Embrapa, pelo Centro Nacional de Pesquisa em Gado de Leite, nos últimos 10 anos, que avaliou o desempenho de vacas holandesas com potencial produtivo de $6.000 \mathrm{~kg}$ lactação ${ }^{-1}$, mostrou que a produção de leite a pasto de “coast-cross” (Cynodon), quando comparada com sistema em confinamento, foi a mais viável economicamente, apresentando margem de lucratividade $50 \%$ maior, mesmo tendo produzido, aproximadamente, 20\% menos leite.

A região sul do Brasil está situada em latitude privilegiada, permitindo a utilização tanto de espécies forrageiras tropicais como de espécies subtropicais, bem como as espécies temperadas, o que facilita a adoção de sistemas de produção animal em pastagens durante o ano inteiro. Outro privilégio da região sul são as extensas áreas de terra agricultável, onde hoje se concentra boa parte da produção de grãos do país, áreas essas caracterizadas por razoável nível de adoção de tecnologia, em geral muito acima daquele verificado nos estabelecimentos de exploração pecuária. Na medida em que a rotação de culturas se constitua numa necessidade de manejo das áreas agrícolas e que a alimentação baseada no uso de pastagens seja um caminho vislumbrado para a diminuição de custos na atividade leiteira, origina-se uma rara oportunidade de integração dessas atividades visando à otimização do sistema (MORAES, 1991).

Vários estudos relatam estratégias de suplementação a pasto, no entanto, poucas são as informações de quais seriam os níveis ideais de combinação entre oferta de forragem e níveis de suplementação que poderiam otimizar a eficiência produtiva e econômica para o produtor de leite. Dessa forma, o objetivo do presente trabalho foi avaliar a rentabilidade de sistemas de produção de leite, à medida em que se diminui a proporção das necessidades nutricionais das vacas atendidas pela suplementação.

Utilizou-se como estratégia de comparação o uso de diferentes níveis de suplementação com dieta total, simulando os níveis de intensificação observados na região dos Campos Gerais do Paraná, onde, no maior nível de suplementação, os animais independem dos nutrientes fornecidos pelo pasto. As pastagens foram conduzidas de forma integrada à produção agrícola, observando calendários e proporções de áreas discutidos por CARVALHO et al. (2005).

\section{MATERIAL E MÉTODOS}

O trabalho foi conduzido na Fazenda do Instituto Cristão, no município de Castro - PR, localizada na região fisiográfica denominada Primeiro Planalto Paranaense, situada à altitude média de 934 metros, longitude oeste $50^{\circ} 00^{\prime} 25^{\prime}$ 'e latitude sul 2447’28”. O clima da região, segundo a classificação de Köppen, é temperado do tipo Cfb (IAPAR, 1994). O solo da área experimental é do tipo Associação de Cambissolo Haplico, Tb, relevo ondulado + Latossolo Bruno, relevo suave ondulado, ambos Distróficos típicos, textura argilosa, epieutróficos, fase campo subtropical (EMBRAPA/FUNDAÇÃO ABC, 2001).

Para o estudo da análise econômica da produção de leite a pasto e com suplementos, o trabalho foi conduzido de julho de 2004 a abril 2005, em pastagem anual de inverno, implantada após a colheita da soja, com aveia preta (Avena strigosa Schreb.) consorciada 
com azevém anual (Lolium multiflorum Lam.). Os animais permaneceram na pastagem de inverno de julho até outubro de 2004, quando a área foi liberada para o plantio da cultura do milho. Os animais foram então transferidos para a pastagem de verão, constituída de Quicuio (Pennisetum clandestinum), ficando sob avaliação até o mês de abril de 2005.

A área total foi de 32,4ha, com 22,4 hectares no inverno, divididos em 12 piquetes de acordo com os tratamentos. $\mathrm{O}$ experimento teve seqüência no verão com área de 10 hectares, constituindo-se outros 12 piquetes de acordo com os tratamentos. O delineamento utilizado foi o de blocos completos ao acaso, com quatro tratamentos e três repetições. Os tratamentos corresponderam às variações nos níveis de suplementação fornecidos no cocho calculados para atender a mantença e vacas produzindo 28 litros vaca $^{-1}$ dia $^{-1}$ (Tabela 1). A formulação da ração foi elaborada pelo programa Spartan Ration Evaluator versão 2.02b (Michigan State University).

Foram utilizadas 48 vacas leiteiras, sendo 36 da raça Holandesa e 12 da raça Jérsei, que foram divididas em doze grupos de quatro animais por parcela, procurando equivalência na raça, no peso, no estágio de lactação e na produção de leite .

O método de pastejo foi o de lotação contínua, utilizando como critério de manejo a manutenção de altura da pastagem, com a utilização da técnica put and take descrita por MOTT \& LUCAS (1952). Foram usados quatro animais testers por unidade experimental, acima descritos, e um número variável de animais reguladores, compostos por vacas secas e novilhas, utilizados de forma a manter a altura do pasto desejada em torno de $20 \mathrm{~cm}$, sendo esta a altura necessária para potencializar a produção animal (CARVALHO et al., 2005).

O ajuste da carga animal foi realizado semanalmente com a entrada ou a retirada de animais reguladores, após avaliação da altura do pasto, por meio da utilização de um tipo de régua denominado sward stick (BARTHRAM, 1985).

A produção de leite por vaca foi monitorada duas vezes por semana e a cada duas semanas foram coletadas amostras individualizadas por animal. As amostras de leite foram coletadas em recipiente próprio, contendo conservante bronopol ${ }^{\circledR}$ (2-bromo-2nitropropano-1,3-diol). Após cada coleta, as amostras foram enviadas ao laboratório do Programa de Rebanhos Leiteiros do Paraná, da APCBRH, em Curitiba. As amostras de leite foram analisadas para se quantificar as percentagens de gordura e proteína no equipamento Bentley $2000^{\circledR}$, por leitura de absorção infravermelho. Para a contagem de células somáticas totais, empregou-se o equipamento modelo Somacount $500^{\circledR}$, por citometria de fluxo.

A análise econômica foi realizada para o período anual de acordo com a planilha proposta pelo Sistema de Acompanhamento do Custo de Produção de Leite no Estado do Paraná (FAEP, 1996). Essa proposta de acompanhamento resulta em cálculo de custo de produção seguro e aplicável, pois foi definida após a determinação dos sistemas de produção representativos dos produtores de leite paranaenses.

Os custos de produção de leite foram divididos em custos variáveis e custos fixos. O custo de produção é igual à soma de ambos, menos as receitas indiretas da atividade. Para a apropriação dos resultados na planilha de custo de produção, considerou-se a propriedade estudada (Instituto Cristão - Castro - PR), como um todo, apropriando-se os coeficientes técnicos do rebanho com os resultados de cada tratamento estudado.

Os dados foram analisados dentro de cada época separadamente, segundo delineamento de blocos ao acaso, com quatro tratamentos e três repetições. As variâncias dos tratamentos foram testadas quanto a

Tabela 1 - Quantidades de silagem de milho, concentrado, minerais, teores de proteína bruta (PB, em \%), nutrientes digestíveis totais (NDT, em \%) e peso médio das vacas durante o período experimental. Castro - PR, 2005.

\begin{tabular}{|c|c|c|c|c|c|c|c|}
\hline Tratamentos & $\begin{array}{l}\text { Silagem de } \\
\text { milho (kg) }\end{array}$ & $\begin{array}{c}\text { Concentrado } \\
\text { (kg) }\end{array}$ & $\operatorname{Bicox}^{1}(g)$ & $\mathrm{SMBL}^{2}$ (g) & $\mathrm{NDT}^{3}(\%)$ & $\mathrm{PB}^{4}(\%)$ & $\begin{array}{c}\text { Peso médio } \\
\text { das vacas (kg) }\end{array}$ \\
\hline 20\% de suplementação & 7,55 & 1,67 & 35 & 225 & 60,79 & 16,05 & 496 \\
\hline 45\% de suplementação & 17,95 & 3,98 & 90 & 145 & 63,34 & 15,92 & 498 \\
\hline $65 \%$ de suplementação & 27,21 & 6,01 & 125 & 85 & 65,49 & 15,80 & 505 \\
\hline $100 \%$ de suplementação & 41,33 & 8,96 & 205 & 50 & 68,54 & 15,54 & 500 \\
\hline
\end{tabular}

${ }^{1}$ Suplemento mineral tamponante para bovinos de leite.

${ }^{2}$ Suplemento mineral para bovinos de leite.

${ }^{3}$ Nutrientes digestíveis totais (\%)

${ }^{4}$ Proteína bruta (\%). 
sua homogeneidade pelo teste de Bartlett. As variáveis, cujas variâncias dos tratamentos se mostraram homogêneas, foram submetidas à análise de variância e, se apresentaram diferenças significativas pelo teste de $\mathrm{F}$, tiveram suas médias comparadas pelo teste de Tukey em nível de 5\% de probabilidade. As análises foram feitas utilizando o programa estatístico MSTAT (1991).

\section{RESULTADOS E DISCUSSÃO}

Para a discussão dos resultados, as variáveis analisadas foram agrupadas em produção de leite (litros/vaca/dia) e qualidade do leite (gordura (\%), proteína (\%) e contagem de células somáticas - CCS (x1.000), para os períodos de inverno de 2004 e verão 2004/2005. Além dos dados de produção e qualidade do leite, foram analisados os custos de produção e análise econômica da produção de leite para o período de 2004/2005.

Para o período de inverno de 2004, a análise de variância e o teste de comparação de médias não revelaram diferenças estatísticas significativas entre as médias das produções de leite, do teor de gordura, do teor de proteína e da contagem de células somáticas (Tabela 2).

As produções observadas neste período, nos tratamentos 3 e 4 (65 e 100\% de suplementação), confirmam relatos de BRANCO e CECATO (2002), em que afirmaram que a resposta em produção de leite à suplementação se comporta de acordo com a "lei de produtividade decrescente” e, apesar do aumento da suplementação de $5,77 \mathrm{~kg} \mathrm{vaca}^{-1} \mathrm{dia}^{-1}$ para $8,55 \mathrm{~kg} \mathrm{vaca}^{-1}$ dia $^{-1}$, não houve resposta à produção de leite, produzindo 24,78 litros vaca ${ }^{-1}$ dia $^{-1}$ e 24,49 litros vaca ${ }^{-1}$ $\mathrm{dia}^{-1}$, respectivamente. Ainda segundo esses autores, o uso de suplementação concentrada deve-se limitar a $6 \mathrm{~kg}$ vaca $^{-1} \mathrm{dia}^{-1}$, pois níveis mais baixos produzem melhor retorno econômico e apresentam menor efeito de substituição.
Os resultados para produção e qualidade do leite para o período de verão 2004/2005 são apresentados na tabela 3. O tratamento 4 (100\% de suplementação) apresentou produção superior do que no tratamento 1 e 2 com $20 \%$ e $45 \%$ de suplementação, respectivamente. As respostas de produção nos tratamentos 2 e 3 (45\% e 65\% de suplementação), com 3,78 e $5,77 \mathrm{~kg}$ de suplementação concentrada por vaca $\mathrm{dia}^{-1}$, são próximas àquelas obtidas por ALVIM et al. (1996), que suplementaram vacas leiteiras com 3 e $6 \mathrm{~kg}$ de concentrado por vaca/dia e obtiveram $17,4 \mathrm{~kg}$ e $20,5 \mathrm{~kg} \mathrm{vaca}^{-1} \mathrm{dia}^{-1}$, em condições tropicais.

No tratamento 2 , em que as vacas receberam 3,78kg de concentrado por dia, a produção média de leite foi inferior àquela relatada por FONTANELI et al. (2004), que relataram alcançar produções de 20,21kg de leite vaca ${ }^{-1}$ dia $^{-1}$, com suplementação de $2,73 \mathrm{~kg}$ diários, em pastagem perene de verão (Quicuio).

Para o cálculo do custo de produção, considerou-se a propriedade estudada (Instituto Cristão - Castro - PR), com o rebanho estabilizado. Aqueles animais que comporiam o aumento do rebanho foram descartados e seus valores consignados como receita com venda de animais e descontados no custo de produção do leite. A propriedade foi considerada como um todo, e não somente os tratamentos estudados, apropriando-se os coeficientes técnicos do rebanho com os resultados de cada tratamento.

Na tabela 4 são apresentadas as medidas de desempenho econômico da atividade leiteira. O tratamento 1 (20\% de suplementação) apresentou margem bruta $22 \%$ superior ao tratamento 4 , devido aos menores desembolsos para aquisição de insumos para alimentação. Estes resultados são semelhantes aos obtidos por VILELA et al.(1993), que registraram margem bruta do sistema de produção de leite a pasto $32 \%$ superior ao sistema confinado.

O tratamento 1 (20\% de suplementação) apresentou o menor custo total por litro de leite, mesmo tendo apresentado a menor produção por vaca, com

Tabela 2 - Produção e qualidade do leite produzido em pastagem de inverno segundo diferentes níveis de suplementação. Castro -PR, 2004.

\begin{tabular}{lcccc}
\hline Tratamentos & l Vaca ${ }^{-1}$ dia $^{-1}$ & \%Gordura & \%Proteína & CCS $^{1}(x 1.000)$ \\
\hline T1 $20 \%$ suplementação & $22,02 \mathrm{~A}$ & $3,93 \mathrm{~A}$ & $3,39 \mathrm{~A}$ & $603 \mathrm{~A}$ \\
T2 45\% suplementação & $22,51 \mathrm{~A}$ & $3,70 \mathrm{~A}$ & $3,32 \mathrm{~A}$ & $317 \mathrm{~A}$ \\
T3 65\% suplementação & $24,78 \mathrm{~A}$ & $3,77 \mathrm{~A}$ & $3,28 \mathrm{~A}$ & $726 \mathrm{~A}$ \\
T4 100\% suplementação & $24,49 \mathrm{~A}$ & $3,85 \mathrm{~A}$ & $3,29 \mathrm{~A}$ & $233 \mathrm{~A}$ \\
\hline
\end{tabular}

Médias na mesma coluna, seguidas da mesma letra, não diferem estatisticamente pelo teste de Tukey ao nível de 5\% de probabilidade. ${ }^{1}$ Contagem de Células Somáticas. 
Tabela 3 - Produção e qualidade do leite produzido em pastagem de verão segundo diferentes níveis de suplementação. Castro -PR, 2005.

\begin{tabular}{lcccc}
\hline Tratamentos & l Vaca ${ }^{-1}$ dia $^{-1}$ & \%Gordura & \%Proteína & CCS $^{1}(x 1.000)$ \\
\hline T1 20 \% suplementação & $15,92 \mathrm{C}$ & $3,49 \mathrm{~A}$ & $3,07 \mathrm{~A}$ & $484 \mathrm{~A}$ \\
T2 45\% suplementação & $17,85 \mathrm{BC}$ & $3,45 \mathrm{~A}$ & $3,24 \mathrm{~A}$ & $645 \mathrm{~A}$ \\
T3 65\% suplementação & $22,63 \mathrm{AB}$ & $3,40 \mathrm{~A}$ & $3,13 \mathrm{~A}$ & $714 \mathrm{~A}$ \\
T4 100\% suplementação & $26,98 \mathrm{~A}$ & $3,60 \mathrm{~A}$ & $3,16 \mathrm{~A}$ & $316 \mathrm{~A}$ \\
\hline
\end{tabular}

Médias na mesma coluna, seguidas da mesma letra, não diferem estatisticamente pelo teste de Tukey ao nível de 5\% de probabilidade. ${ }^{1}$ Contagem de Células Somáticas.

18,36 l vaca $^{-1} \mathrm{dia}^{-1}$, média anual ponderada (inverno e verão). Este resultado é justificado devido ao menor desembolso para alimentação. Confirmando relatos de HOLMES e WILSON (1989), que afirmaram que os custos são sensivelmente diminuídos quando se consegue manter rebanhos produtivos à pasto, utilizando recursos forrageiros naturais.

Todos os sistemas de produção apresentaram margem bruta positiva, com sobrevivência garantida no curto prazo. O tratamento 1 apresentou o melhor resultado para margem bruta, indicando menor desembolso no sistema de produção, enquanto que o tratamento 4 , com $100 \%$ de suplementação, apresentou a menor margem bruta, com maior desembolso no sistema de produção, principalmente devido aos custos com concentrados.

Esses resultados estão de acordo com os reportados por HOFFMANN et al. (1993), VILELA et al. (1996) e FONTANELI (1991), citados por MATOS (2002), em que afirmam que, apesar de a receita proveniente do leite produzido à base de pastagem ser menor do que no sistema em confinamento, a margem bruta tem sido superior.

$\mathrm{Na}$ análise da margem líquida, todos os tratamentos apresentam resultados positivos, indicando que a atividade é estável, com possibilidade de expansão, e que tem possibilidades de se manter por longo prazo. Os melhores resultados foram apresentados pelos tratamentos 1 e 3 com margem líquida de R \$ 0,13 e R \$ 0,1062 por litro de leite produzido, indicando que nestes sistemas de produção o capital imobilizado está sendo utilizado de maneira mais adequada e com melhor retorno econômico sobre o investimento.

\section{CONCLUSÕES}

O tratamento 1, com 20\% de suplementação, apresentou o melhor resultado econômico, com custo operacional total de $\mathrm{R} \$ 0,4635$ litro $^{-1}$ de leite produzido e margem líquida de $\mathrm{R} \$ 0,13$ litro $^{-1}$.

Os custos são sensivelmente reduzidos quando se consegue manter rebanhos produtivos à base de pastagem, utilizando-se recursos forrageiros de boa qualidade. Economicamente, o sistema mais dependente da pastagem apresentou o melhor resultado. Portanto, ele pode permitir maior flexibilidade quanto à inversão de sistemas de produção, podendo ser intensificado ou desintensificado, dependendo da conjuntura econômica.

Tabela 4 - Medidas de desempenho econômico da atividade leiteira, com diferentes níveis de suplementação, no período de maio/2004 a abril de 2005, Castro - PR, 2005.

\begin{tabular}{|c|c|c|c|c|}
\hline \multirow{2}{*}{ Descrição } & \multicolumn{4}{|c|}{ Sistemas de produção (tratamentos) } \\
\hline & $20 \%$ & $45 \%$ & $65 \%$ & $100 \%$ \\
\hline Receita total $\left(\mathrm{R} \$ \mathrm{l}^{-1}\right)$ & 0,5936 & 0,5922 & 0,5890 & 0,5874 \\
\hline Custo variável $\left(\mathrm{R} \$ \mathrm{l}^{-1}\right)$ & 0,3738 & 0,4128 & 0,4081 & 0,4506 \\
\hline Custo oper. Total $\left(\mathrm{R} \$ \mathrm{l}^{-1}\right)$ & 0,4636 & 0,4968 & 0,4827 & 0,4838 \\
\hline Margem bruta $\left(\mathrm{R} \$ \mathrm{l}^{-1}\right)$ & 0,2198 & 0,1794 & 0,1810 & 0,1368 \\
\hline Margem líquida $\left(\mathrm{R} \$ \mathrm{l}^{-1}\right)$ & 0,1300 & 0,0954 & 0,1062 & 0,1036 \\
\hline
\end{tabular}

$\mathrm{RT}=$ venda de leite + venda de animais descarte.

$\mathrm{CV}$ = Concentrados e minerais, forragens, vacinas e medicamentos, inseminação artificial, energia e combustíveis, conservação e reparos, assistência técnica, juros sobre o capital de giro, impostos e taxas, despesas gerais e mão-de-obra.

COT = Custo variável + depreciação de máquinas e equipamentos e benfeitorias.

Ciência Rural, v.38, n.2, mar-abr, 2008. 


\section{REFERÊNCIAS}

ALVIM, M.J. et al. Efeitos de dois níveis de concentrado sobre a produção de leite de vacas da raça holandesa em pastagem de coast-cross. In: REUNIÃO ANUAL DA SOCIEDADE BRASILEIRA DE ZOOTECNIA, 33., 1996. Fortaleza, CE. Anais... Fortaleza: SBZ, 1996 . p.172-173.

BARTHRAM, G.T. Experimental techniques: the HFRO sward stick. Aberdeen: Hill Farming Research Organization/ Biennial Report, 1985. p.29-30.

BRANCO, A.F.; CECATO, U. Estratégias de suplementação e vacas leiteiras a pasto. I n: SUL-LEITE: SIMPÓSIO SOBRE A SUSTENTABILIDADE DA PECUARIA LEITEIRA NA REGIÃO SUL DO BRASIL, 2002, Maringá, PR. Anais... Maringá: Universidade Estadual de Maringá, 2002. p.97-110.

CARVALHO, P.C.F. et al. O estado da arte em integração lavoura-pecuária. In: GOTTSCHALL, C.S. et al. (Org.). Produção animal: mitos, pesquisa e adoção de tecnologia. Canoas-RS: Ulbra, 2005. p.7-44.

EMBRAPA/FUNDAÇÃO ABC. Levantamento semidetalhado de solos - Município de Castro. Relatório Interno. Castro -PR: EMBRAPA/SOLOS, EMBRAPA/FLORESTAS, FUNDAÇÃO ABC, 2001. 86p.

FEDERAÇÃO DA AGRICULTURA DO ESTADO DO PARANÁ. Sistema de acompanhamento do custo de produção do leite no Paraná. Curitiba: FAEP; OCEPAR, 1996. 99p.

FONTANELI, R.S. et al. Produção de leite em pastagens tropicais em Passo Fundo (RS). In: GRASSLAND ECOPHYSIOLOGY AND GRAZING ECOLOGY, 2., 2004, Curitiba, PR. Anais... Curitiba: UFPR, 2004. CD ROM.

HOLMES, C.W. ; WILSON, G.F. Produção de leite a pasto. Campinas, SP: Instituto Campineiro de Ensino Agrícola, 1989. 708p.

HOLMES, C.W. Produção de leite a baixo custo em pastagens: uma análise do sistema neozelândes. In: CONGRESSO
BRASILEIRO DE GADO LEITEIRO, 2., 1995, Piracicaba, SP. Anais... Piracicaba: FEALQ, 1995. p.69-95.

INSTITUTO AGRONÔMICO DO PARANÁ. Cartas Climáticas do Estado do Paraná 1994. Londrina, PR., 1994. 49p. (IAPAR. Documento,18).

MATOS, L.M. Estratégias para redução do custo de produção de leite e garantia de sustentabilidade da atividade leiteira. In: SUL-LEITE - SIMPÓSIO SOBRE A SUSTENTATABILIDADE DA PECUÁRIA LEITEIRA NA REGIÃO SUL DO BRASIL, 2002, Maringá,PR. Anais... Maringá: Universidade Estadual de Maringá, 2002. p.156-183.

MSTAT - Microcomputer Statistical Program. East Lansing/Michigan: Michigan State University, 1991. 400p.

MORAES, A. Produtividade animal e dinâmica de uma pastagem de pangola (Digitaria decumbens stent). Azevém (Lolium multiflorum Lam) e trevo branco (Trifolium repens L.), submetidas a diferentes pressões de pastejo. 1991. 200f. Tese (Doutorado em Zootecnia) - Curso de Pós-graduação em Zootecnia, Universidade Federal do Rio Grande do Sul.

MOTT, G.O.; LUCAS, H.L. The design, conduct and interpretation of grazing trials on cultivated and improved pastures. In: INTERNATIONAL GRASSLAND CONGRESS, 6., 1952, Pennsylvania. Proceedings... Pennsylvania: State College, 1952. p.1380-1385.

VILELA, D. et al. Comparação entre os sistemas de pastejo em coast-cross (Cynodon dactylon, L.) e o sistema de confinamento para vacas de leite. In: REUNIÃO ANUAL DA SOCIEDADE BRASILEIRA DE ZOOTECNIA, 30., 1993, Rio de Janeiro, RJ. Anais... Rio de Janeiro: SBZ, 1993. p.21.

VILELA, D. et al. Produção de leite de vacas holandesas em confinamento ou em pastagem de coast-cross. Revista Sociedade Brasileira de Zootecnia, v.25, n.6, p.1228-1246, 1996. 